\title{
The Water Uptake of Plasticized Poly(vinyl chloride) Solid- Contact Calcium-Selective Electrodes
}

\author{
Tom Lindfors, ${ }^{\text {a, b }}$ Fredrik Sundfors, ${ }^{\mathrm{a}}$ Lajos Höfler,${ }^{\mathrm{c}, \mathrm{d}}$ Róbert E. Gyurcsányi ${ }^{\mathrm{c}, \mathrm{e}}$ \\ a Laboratory of Analytical Chemistry, Process Chemistry Centre, Åbo Akademi University, Biskopsgatan 8, FI-20500 Åbo, Finland \\ b Academy of Finland, Helsinki, Finland \\ c Department of Inorganic and Analytical Chemistry, Budapest University of Technology and Economics, H-1111 Budapest, Szt. \\ Géllert tér 4, Hungary \\ d Department of Chemistry, The University of Michigan, 930 N. University Ave., Ann Arbor, MI 48109-1055, USA \\ e Research Group of Technical Analytical Chemistry of the Hungarian Academy of Sciences, H-1111 Budapest, Szt. Géllert tér 4, \\ Hungary \\ *e-mail: Tom.Lindfors@abo.fi
}

Received: April 18, 2011

Accepted: June 30, 2011

\begin{abstract}
A hyphenated method based on FTIR-ATR and electrochemical impedance spectroscopy has been applied to simultaneously measure the water uptake, changes in the bulk resistance and potential of plasticized poly(vinyl chloride) (PVC) based $\mathrm{Ca}^{2+}$-selective coated-wire (CaCWE) and solid-contact electrodes (CaSCISEs). Most of the water uptake of the ion-selective membranes (ISMs) used in both electrode types took place within the first $9 \mathrm{~h}$ in $10^{-3} \mathrm{M} \mathrm{CaCl}_{2}$ showing good correlation with the stabilization of the individual electrode potentials. The bulk resistance of the ISMs of the CaCWEs and the CaSCISEs with poly(3-octylthiophene) (POT) as the solid-contact (SC) increased most during the first $18 \mathrm{~h}$ in $10^{-3} \mathrm{M} \mathrm{CaCl}_{2}$. The increase in the resistance was found to be related to the exchange of $\mathrm{K}^{+}$for $\mathrm{Ca}^{2+}$ in the ISM and the formation of the $\mathrm{Ca}^{2+}$-ionophore (ETH 5234) complex having a lower diffusivity than the free $\mathrm{K}^{+}$ions. In contrary to previously published results on silicone rubber based SCISEs and poly(methyl methacrylate):poly(n-decyl methacrylate) membranes containing POT, the plasticized PVC-based CaSCISEs with POT as the SC had a higher water uptake than the CaCWEs. The CaSCISEs had a detection limit of $2 \times$ $10^{-8} \mathrm{M} \mathrm{Ca}^{2+}$ and a good potential reproducibility of $148.9 \pm 1.0 \mathrm{mV}$ in $10^{-4} \mathrm{M} \mathrm{CaCl}_{2}$.
\end{abstract}

Keywords: Solid-contact ion-selective electrode, Poly(3-octylthiophene), Plasticized poly(vinyl chloride), Water uptake, Potential stability, FTIR-ATR spectroscopy, Electrochemical impedance spectroscopy

DOI: 10.1002/elan.201100219

\section{Introduction}

Even though the potential stability and reproducibility of the liquid contact ISEs are still hard to be matched, the solid contact ion-selective electrodes (SCISEs) have become one of the preferred designs for the ISE fabrication. The SC construction has definite advantages in making the manufacturing, miniaturization, and handling of the ISEs easier. Among the various SC materials proposed, the electrically conducting polymer (CP) based SCISEs $[1,2]$ have been the most extensively studied. Initially, these studies focused on understanding the ion-toelectron transducing and the potential stabilizing mechanisms of CPs [2-6] in parallel with testing a large number of CPs and dopants [7-14]. However, more recently it was realized that while thermodynamically well-defined interfaces can be now designed by using various materials as SCs, their performance is readily affected by small amounts of water originating from transmembrane water fluxes $[15,16]$.
Upon formation of an aqueous layer beneath the ionselective membrane (ISM), both the SCISEs and the coated-wire ISEs (CWEs) are converted into conventional liquid contact ISEs with an extremely small inner solution volume. Therefore, even minute transmembrane fluxes of primary and interfering ions can cause already large ion activity changes within the aqueous layer leading to potential instability and memory effects. Additionally, the CP-based SCs can in some cases also be partially dedoped (reduced) to the electrically non-conducting form due to the water uptake resulting in release of cations or anions from the $\mathrm{CP}$ into the SC/ISM interfacial region [17]. Thus the formation of an aqueous layer is a major source of potential instability and an obstacle in fabricating SCISEs for ultratrace analysis. For all these reasons it is extremely important to reduce the water uptake of both the ISM and the SC, which ultimately means that the use of highly hydrophobic materials are emerging as an additional essential criterion in designing SCISEs with high potential stability. 
We have previously studied the water uptake of different types of relevant ion-selective membranes [18-20] and SC materials [20] to understand the water uptake mechanism and also its effects on the potential stability of the ISEs. Apart from early water uptake studies $[16,21,22]$, our investigations were performed with SCISEs and CWEs (asymmetrical setups) that despite of their immediate practical relevance has gained much less attention [18-20,22-26]. We have recently shown the importance of using hydrophobic membrane materials (ISMs and SCs) in SCISEs to obtain stable potentials with a hyphenated method utilizing FTIR-ATR $[18,19]$ and electrochemical impedance spectroscopy (EIS) [20]. Despite of alternative hydrophobic ISM materials like silicone rubber (SR) [27-33] and different self-plasticized poly(acrylate) copolymers [34,35], plasticized poly(vinyl chloride) (PVC) [36] is still the most commonly used membrane material for ISEs due to its rather high tensile strength, chemical inertness, easy preparation procedure and good compatibility with most ionophores.

Therefore, in this paper, we investigate the water uptake of $\mathrm{Ca}^{2+}$-selective plasticized PVC-based SCISEs (CaSCISEs) having poly(3-octylthiophene) (POT) as SC and its influence on the electrode characteristics during the initial conditioning $(24 \mathrm{~h})$ in an aqueous electrolyte solution. We have used the previously developed hyphenated method based on FTIR-ATR and EIS [20] to determine the potential and impedance changes of the CaSCISEs simultaneously with the water uptake. The obtained results are compared with SR based CaSCISEs [20].

\section{Experimental}

\subsection{Chemicals}

High molecular weight poly(vinyl chloride) (PVC), bis(2ethylhexyl) sebacate (DOS), potassium tetrakis[3,5-bis(trifluoromethyl)phenyl]borate (KTFPB), calcium ionophore IV (ETH 5234) and tetrahydrofuran (THF), were all of Selectophore grade and received from Fluka. The regioregular poly(3-octylthiophene-2,5-diyl $)\left(M_{\mathrm{n}}=34000\right)$ with an electrical conductivity of $10^{-6} \mathrm{Scm}^{-1}$ was purchased from Sigma-Aldrich.

The experimental procedures follow those described previously [20].

\subsection{Electrode Preparation}

\subsubsection{Electrodes for FTIR-ATR Measurements}

(a) CaCWEs: The $\mathrm{Ca}^{2+}$-selective ISMs with thicknesses of ca. $250 \mu \mathrm{m}$ were deposited by drop casting $(2 \times 75 \mu \mathrm{L})$ on Pt-coated zinc selenide ( $\mathrm{ZnSe})$ reflection elements (Crystran Limited; Angle of incidence: $45^{\circ}$ ). The membrane solution dissolved in THF had a dry weight of $20.0 \mathrm{wt} \%$ and consisted of $32.92 \mathrm{wt} \%$ PVC, $65.83 \mathrm{wt} \%$ DOS, $0.80 \mathrm{wt} \%(10 \mathrm{mmol} / \mathrm{kg}$ of the membrane) ETH
5234 and $0.45 \mathrm{wt} \%(5 \mathrm{mmol} / \mathrm{kg})$ KTFPB. The ISMs were allowed to dry at least for $24 \mathrm{~h}$ prior to the FTIR-ATR measurements. The experimental procedures have been described in detail elsewhere $[18,20]$.

(b) CaSCISEs: $50 \mu \mathrm{L}$ of regioregular POT $(10 \mathrm{mg} / \mathrm{mL}$ in chloroform) was applied by drop casting on the Ptcoated $\mathrm{ZnSe}$ substrates and allowed to dry overnight before applying the upper $\mathrm{Ca}^{2+}$-selective ISM by drop casting on top of the POT layer. The thickness of the sputtered Pt-coating was $15 \mathrm{~nm}$.

The Pt-coated ZnSe substrates will hereafter be denoted as $\mathrm{ZnSe}$ if not otherwise stated.

\subsubsection{Electrodes for Potentiometric Measurements}

(a) CaCWEs: ISMs with the same composition as in the FTIR-ATR measurements and with a thickness of ca. 220-240 $\mu \mathrm{m}$ were deposited on glassy carbon (GC) electrodes with PEEK bodies by applying $45 \mu \mathrm{L}$ of the membrane solution on top of the GC/PEEK electrodes (outer diameter: $6 \mathrm{~mm}$ ). The ISMs were allowed to dry overnight prior to the potentiometric measurements.

(b) CaSCISEs: $2 \times 0.5 \mu \mathrm{L}$ of a POT solution $(10 \mathrm{mg} / \mathrm{mL}$ in chloroform) was applied as the SC layer on the GC substrate and was allowed to dry for $10 \mathrm{~min}$ before applying $45 \mu \mathrm{L}$ of the $\mathrm{Ca}^{2+}$-selective ISM cocktail on top of the POT layer. The ISM covered the entire surface of the GC/PEEK electrode.

\subsection{FTIR-ATR Measurements}

The FTIR-ATR setup has been described in detail previously [18]. Before starting the FTIR-ATR measurements, the sample compartment was purged with dry air for $30 \mathrm{~min}$. The background spectrum as well as the first FTIR spectrum in the measurement sequence was measured without electrolyte. After measuring the first spectrum, the cell was filled with $10^{-3} \mathrm{M} \mathrm{CaCl}_{2}$. The FTIR spectra were recorded with $60 \mathrm{~s}$ intervals during the two first hours of the measurements and with 15 min intervals during the rest of the total measurement time of $24 \mathrm{~h}$. The FTIR-ATR measurements were done with a Bruker IFS 66/S spectrometer equipped with a DTGS detector. The spectra were measured with a resolution of $4 \mathrm{~cm}^{-1}$ and 32 interferograms with a signal gain of 32 were recorded for each spectrum.

\subsection{Electrochemical Impedance Measurements}

Impedance spectra within the frequency range of $100 \mathrm{kHz}-10 \mathrm{mHz}$ were measured once every hour in $10^{-3} \mathrm{M} \mathrm{CaCl}_{2}$ during $24 \mathrm{~h}$ with an Autolab potentiostat PGSTAT20 equipped with an impedance module (FRA2). All impedance measurements were done in the single sine mode at the open circuit potential with an amplitude $(\Delta E)$ of $100 \mathrm{mV}$ and it took ca $10 \mathrm{~min}$ to measure the impedance spectrum. Additionally, the open circuit potential was recorded once every $15 \mathrm{~min}$. $\mathrm{A} \mathrm{Ag} / \mathrm{AgCl}-$ 
wire was used as a quasireference electrode in the impedance measurements. The impedance and the FTIR-ATR measurements were started simultaneously.

\subsection{Potentiometric Measurements}

(a) Selectivity coefficients: The unbiased selectivity coefficients of $\mathrm{Ca}^{2+}$ against $\mathrm{Na}^{+}, \mathrm{K}^{+}, \mathrm{H}^{+}$and $\mathrm{Mg}^{2+}$ for the CaCWEs and CaSCISEs were measured in $0.1 \mathrm{M}$ chloride solutions prepared with deionized water. A double junction $\mathrm{Ag} / \mathrm{AgCl}$ electrode filled with $3.0 \mathrm{M} \mathrm{KCl}$ and $1.0 \mathrm{M}$ $\mathrm{KCl}$ in the inner and outer compartments, respectively, was used as the reference electrode.

(b) Potentiometric calibrations: All electrodes were calibrated from $10^{-4} \mathrm{M}$ to $3 \times 10^{-12} \mathrm{M} \mathrm{CaCl}_{2}$ in $100 \mathrm{~mL}$ PTFE beakers with an automatic diluting system (Metrohm 700 Dosino and 711 Liquino controller). The dilutions were done by automatically removing $50 \mathrm{~mL}$ of the previous sample solution after a contact time of $3 \mathrm{~min}$ and replacing it with the same amount of deionized water. The electrodes were first conditioned at least for $24 \mathrm{~h}$ in a $10^{-3} \mathrm{M} \mathrm{CaCl}_{2}$ solution and then in $10^{-5} \mathrm{M} \mathrm{CaCl}_{2}$ overnight before they were conditioned prior to the potentiometric calibrations for $3 \mathrm{~h}$ in a $10^{-9} \mathrm{M} \mathrm{CaCl}_{2}$ solution containing $10^{-5} \mathrm{M} \mathrm{NaCl}$ as the background electrolyte. This solution was changed to a fresh one every hour. All potentiometric measurements were done in stirred solutions with a 16-channel high input impedance $\left(10^{15} \Omega\right)$ voltmeter (Lawson Labs Inc., Malvern, PA).

\subsection{Mathematical Modeling of Water Diffusion Coefficients in the CaCWE Membranes}

The mathematical modeling of the diffusion coefficients of water in the CaCWE membranes has been described in detail elsewhere [18]. The diffusion coefficients of water were modeled from the strong $\mathrm{OH}$-stretching vibrational bands of water in the wavenumber region of 2960$3750 \mathrm{~cm}^{-1}$. Most obviously, the water uptake is diffusion controlled at longer times, but it is unclear whether this is also the case at the very beginning of the water uptake process. It's possible that swelling of the plasticized PVC matrix creates transient strain, which causes stress and affects the diffusion (stress-dependent diffusion) [37].

\section{Results and Discussion}

\subsection{Water Uptake}

We have shown previously that a very low water content at the $\mathrm{ZnSe} / \mathrm{SC}$ interface correlated with superior potential stability of hydrophobic CaSCISEs having SR (RTV 3140 ) as the outer ISM and POT as the SC. Practically no potential drift was observed for initially unconditioned CaSCISEs when contacted with $10^{-3} \mathrm{M} \mathrm{CaCl}_{2}$ for $24 \mathrm{~h}$, indicating that the SR-based CaSCISEs were conditioningfree. Mathematical modeling showed that the water diffusion coefficients in the POT solid-contact layer were ap- proximately two orders of magnitude lower than in the SR-based ISM explaining why POT prevented water from reaching the $\mathrm{ZnSe} / \mathrm{SC}$ interface. The water content at the ZnSe/ISM interface and the potential drift of CaCWEs were considerably higher than for the CaSCISEs. Consequently, in addition to the beneficial ion-toelectron transduction properties of the SC layer, it also functions, if properly chosen, as a water barrier contributing to an improved potential stability.

The water uptake of plasticized PVC-based CaCWEs in deionized water, which was recently reported $[18,23]$, was much higher than for the corresponding SR-based CaCWEs $[18,19]$. However, no attempts have been done to determine the water uptake of plasticized PVC-based SCISEs and the influence of the SC on the electrode characteristics during the initial conditioning $(24 \mathrm{~h})$ in an aqueous electrolyte solution.

The water uptake of the CaSCISE and the CaCWE structures was therefore measured with the new hyphenated method for $24 \mathrm{~h}$ in $10^{-3} \mathrm{M} \mathrm{CaCl}_{2}$ and the $\mathrm{OH}$ stretching band in the FTIR-ATR spectra at ca. 2950$3750 \mathrm{~cm}^{-1}$ was used to follow the water uptake (Figure 1) $[18,19]$. The presence of minor amounts of water was detected at the $\mathrm{ZnSe}$ substrate for both electrode types already after a contact time of $30 \mathrm{~min}$ with the electrolyte solution showing that water penetrates rather rapidly through the CaCWE (Figure 1a) and CaSCISE (Figure $1 \mathrm{~b}$ ) structures to the underlying $\mathrm{ZnSe}$ substrate. The spectra in Figure 1 indicate that most of the water uptake took place during the first $9 \mathrm{~h}$ of the measurement after which the absorbance increased only slightly.

A model with two diffusion coefficients, $D_{1}=1.0 \times$ $10^{-7} \mathrm{~cm}^{2} \mathrm{~s}^{-1}$ and $D_{2}=1.0 \times 10^{-8} \mathrm{~cm}^{2} \mathrm{~s}^{-1}$, which are in good accordance with previously reported values [18], was sufficient to describe the water uptake of the PVC-based $\mathrm{CaCWE}$ membranes. It was recently shown that a model with three water diffusion coefficients had to be used for SR-based CaCWEs and poly(methyl methacrylate):poly(n-decyl methacrylate) (PMMA:PDMA) membranes containing POT $[20,38]$. This indicates that there are differences in the water uptake or water network formation within the plasticized PVC-based ISMs compared to the SR and PMMA:PDMA membranes. The water uptake of a $7 \mu \mathrm{m}$ thick POT film was also best described with a model consisting of three diffusion coefficients, $D_{1}=4.7 \times$ $10^{-10} \mathrm{~cm}^{2} \mathrm{~s}^{-1}, \quad D_{2}=5.1 \times 10^{-11} \mathrm{~cm}^{2} \mathrm{~s}^{-1} \quad$ and $\quad D_{3}=4.7 \times$ $10^{-12} \mathrm{~cm}^{2} \mathrm{~s}^{-1}$ [20], which are all 2.5-4.5 orders of magnitude lower than in the PVC-based CaCWE membranes. It could therefore be expected that the water content at the $\mathrm{ZnSe} / \mathrm{SC}$ interface of the PVC-based CaSCISEs would be lower than for the CaCWEs.

However, in contrary to SR-based CaSCISEs [20] and PMMA:PDMA membranes containing POT [38], which both showed that POT decreased the water content at the $\mathrm{ZnSe} / \mathrm{SC}$ and $\mathrm{ZnSe} / \mathrm{ISM}$ interfaces, the PVC-based CaSCISEs with POT as the SC showed a higher water uptake than the corresponding CaCWEs without POT (Figure 1b). During the drop casting of the outer PVC- 


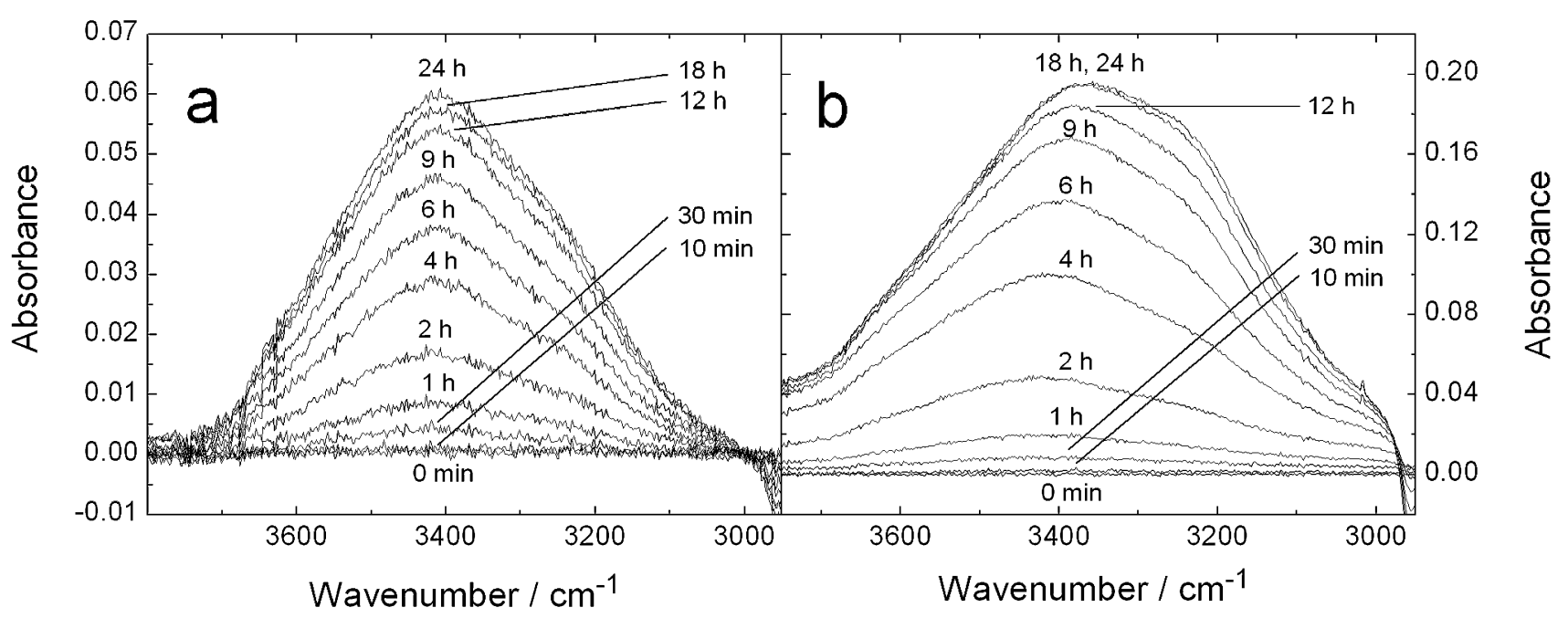

Fig. 1. FTIR-ATR spectra (OH-stretching band) measured in $10^{-3} \mathrm{M} \mathrm{CaCl}_{2}$ during the water uptake (24 h) of (a) the CaCWE and (b) the CaSCISE structures with the thicknesses of $250 \mu \mathrm{m}$ and $252 \mu \mathrm{m}$, respectively.

based CaISM, it was observed that the POT solid-contact deposited on ZnSe was strongly dissolved in the outer ISM, in comparison to the SR-based CaSCISEs where POT was only dissolved to a minor extent. The dissolution of POT in the outer plasticized PVC-based CaISM may influence the water uptake of the CaSCISEs, although the exact reason for the higher water uptake is still unclear.

The influence of the intermixing of plasticized PVC and POT was studied by comparing the water uptake of equally thick $(\sim 100 \mu \mathrm{m})$ membranes of POT, plasticized PVC (PVC:DOS, 1:2) and plasticized PVC containing $5 \mathrm{wt} \%$ POT. As shown in Figure 2, the plasticized PVC membrane incorporating $5 \mathrm{wt} \%$ POT had the highest water uptake whereas 'neat' POT had the lowest. In another FTIR-ATR measurement with thicker membranes (not shown here), 1 and $5 \mathrm{wt} \%$ POT was incorporated in plasticized PVC:DOS (1:2) membranes prepared on uncoated $\mathrm{ZnSe}$ reflection elements. The water uptake of these membranes was measured in deionized water and compared with a PVC:DOS $(1: 2)$ membrane without POT. The total integrated absorbance at infinite time of the OH-stretching bands $\left(A_{\mathrm{tot}}\right)$ at $2950-3750 \mathrm{~cm}^{-1}$ $[18,19,38]$, which reflects the total equilibrium water uptake, showed that POT increased the water uptake of the plasticized PVC membrane. The obtained diffusion coefficients and $A_{\text {tot }}$ values are summarized in Table 1. In spite of the fact that the water diffusion coefficients decreased slightly in PVC membranes containing POT, it is still reasonable to assume that the higher water uptake of the CaSCISE is due to the intermixing of the POT solidcontact layer and the plasticized PVC membrane. A considerable phase separation between plasticized PVC and POT was observed in a plasticized PVC membrane containing $10 \mathrm{wt} \%$ POT. One essential difference between the self-plasticized PMMA:PDMA and the SR membranes, and the PVC membranes is that only the PVC membrane contains a plasticizer (DOS). It can therefore

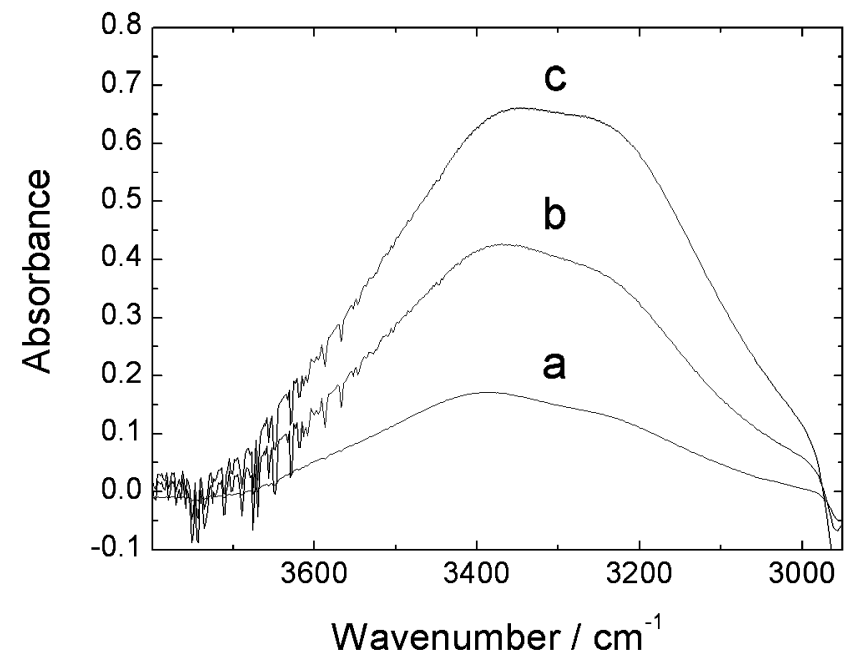

Fig. 2. FTIR-ATR spectra reflecting the water uptake of (a) POT (membrane thickness: $103 \mu \mathrm{m}$ ), (b) plasticized PVC:DOS $(1: 2)(108 \mu \mathrm{m})$ and $(\mathrm{c})$ a plasticized PVC:DOS $(1: 2)$ membrane containing $5 \mathrm{wt} \%$ POT $(103 \mu \mathrm{m})$. The spectra were measured for $24 \mathrm{~h}$ in deionized water.

be speculated that the interaction between the plasticizer and POT can result in structural and morphological changes in the ISM which will increase the water uptake of the CaSCISEs.

\subsection{Potential Stability}

The potential stability of the initially unconditioned CaCWEs and the CaSCISEs was measured in $10^{-3} \mathrm{M}$ $\mathrm{CaCl}_{2}$ simultaneously with the water uptake. The measurement was repeated three times and the general trend observed was that the CaCWEs had a slightly lower drift than the CaSCISEs, even though the difference was not significant. As shown in Figure 3, the initial potential drift of the CaCWE and CaSCISE during the first $9 \mathrm{~h}$ of the 
Table 1. The diffusion coefficients $(D)$ and total integrated absorbances $\left(A_{\text {tot }}\right)$ of plasticized PVC:DOS $(1: 2)$ membranes containing POT.

\begin{tabular}{lllll}
\hline wt $\%$ POT & Thickness $(\mu \mathrm{m})$ & $D_{1}\left(\mathrm{~cm}^{2} \mathrm{~s}^{-1}\right)$ & $D_{1}\left(\mathrm{~cm}^{2} \mathrm{~s}^{-1}\right)$ & $A_{\text {tot }}\left(\mathrm{AU} \mathrm{cm}^{-1}\right)$ \\
\hline 0 & 324 & $(9.4 \pm 0.2) \times 10^{-8}$ & $(9.2 \pm 0.1) \times 10^{-9}$ & $29.2 \pm 0.2$ \\
1 & 324 & $(7.2 \pm 0.1) \times 10^{-8}$ & $(7.7 \pm 0.2) \times 10^{-9}$ & $55.7 \pm 0.4$ \\
5 & 306 & $(6.7 \pm 0.1) \times 10^{-8}$ & $(7.9 \pm 0.1) \times 10^{-9}$ & $79.4 \pm 0.4$ \\
\hline
\end{tabular}

measurement was ca. $30 \mathrm{mV}$ and ca. $40 \mathrm{mV}$, respectively. However, the open circuit potential of the CaCWE showed some fluctuations due to the blocked ZnSe/ISM interface. The slightly higher potential drift of the CaSCISE is consistent with its higher water uptake compared to the CaCWE (Figure 1). After the initial potential drift the potentials of both electrode types stabilized within 9$12 \mathrm{~h}$, which is in accordance with the water uptake showing that the membranes are almost fully equilibrated after $12 \mathrm{~h}$ in contact with $10^{-3} \mathrm{M} \mathrm{CaCl}_{2}$. The $\mathrm{CaCWE}$ and CaSCISE showed only a low potential drift of ca. $3 \mathrm{mV}$ and $-8 \mathrm{mV}$, respectively, during the remaining potential stability measurement (9-24 h).

The potential stability measurements indicate that the potential drift of the PVC-based CaCWEs and CaSCISEs is associated with the amount of water accumulating at the $\mathrm{ZnSe} / \mathrm{ISM}$ or SC interfaces. A lower water content gives a better potential stability, as was previously observed for SR-based CaCWEs and CaSCISEs [20]. However, the very initial potential drift is probably also influenced by changes of the primary ion activity in the ISM phase.

\subsection{Impedance Stability}

The impedance spectra of the CaCWE and CaSCISE were measured in $10^{-3} \mathrm{M} \mathrm{CaCl}_{2}$ every hour simultaneously with the water uptake (Figure 4). The almost complete

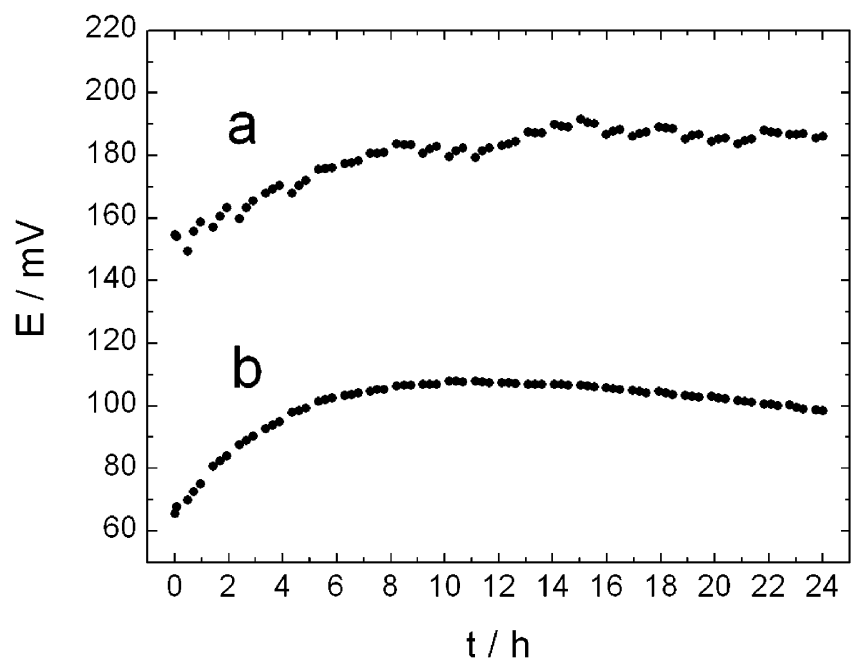

Fig. 3. The potential stability of (a) the CaCWE (membrane thickness: $250 \mu \mathrm{m})$ and (b) the CaSCISE $(252 \mu \mathrm{m})$ measured in $10^{-3} \mathrm{M} \mathrm{CaCl}_{2}$. absence of the low frequency process of the CaSCISEs confirmed that POT improved the charge transfer at the $\mathrm{ZnSe} / \mathrm{SC}$ interface $[39,40]$, whereas the pronounced low frequency process of the $\mathrm{CaCWE}$ is typical for the blocked $\mathrm{ZnSe} / \mathrm{ISM}$ interface.

The biggest changes in the bulk resistance of the CaCWE and CaSCISE membranes took place during the first $12 \mathrm{~h}$ having a value which was $78 \%$ and $83 \%$, respectively, of the bulk resistance after $24 \mathrm{~h}$. Only a slight increase in the bulk resistance was observed after $18 \mathrm{~h}$. The reason for the increasing bulk resistance of the CaCWE and CaSCISE membranes when they were for the first time contacted (conditioned) with $10^{-3} \mathrm{M} \mathrm{CaCl}_{2}$ is most likely related to the exchange of $\mathrm{K}^{+}$(originating from KTFPB) for $\mathrm{Ca}^{2+}$ and the formation of the $\mathrm{Ca}^{2+}$ -ionophore (ETH 5234) complex, which has a lower diffusion coefficient $\left(8.47 \times 10^{-9} \mathrm{~cm}^{2} \mathrm{~s}^{-1}\right.$ [41]) than the $\mathrm{K}^{+}$ions in the membrane phase thus increasing the resistance of the ISM. It was shown earlier that the $\mathrm{K}^{+}$-valinomycin complex had a mobility of 0.65 relative to the free $\mathrm{K}^{+}$ ions in a $\mathrm{K}^{+}$-selective PVC-based ISM supporting the assumption that the increasing bulk resistance during the water uptake was due to the gradual increase of the region rich in $\mathrm{Ca}^{2+}$-ionophore complex [42,43]. After $18 \mathrm{~h}$ most of the $\mathrm{K}^{+}$was exchanged by $\mathrm{Ca}^{2+}$ in the ISM, thus the resistance leveled off. Because of the high stability constant of the $\mathrm{Ca}^{2+}$-ETH5234 $(1: 3)$ complex $(\log \beta=$ $22.06 \pm 0.08$ in a PVC:DOS membrane [44]) it is assumed that the concentration of the free $\mathrm{Ca}^{2+}$ ions and the ion pair formation between $\mathrm{Ca}^{2+}$ and $\mathrm{TFPB}^{-}$in the ISM is negligible and does not contribute to the conductance of the membrane.

The dielectric constants $\left(\varepsilon_{\mathrm{r}}\right)$ of the CaCWE and CaSCISE membranes with well-defined geometry and thickness were practically unaffected by the water uptake in $10^{-3} \mathrm{M} \mathrm{CaCl}_{2}$. Fitting the bulk semicircle to an equivalent circuit consisting of a resistance in parallel with a constant phase element showed that the dielectric constants of the CaCWE and CaSCISE membranes in Figure 4 changed during the water uptake only from $3.4(t=1.9 \mathrm{~h}$; $n=0.908)$ to $3.3(t=23.3 \mathrm{~h} ; n=0.932)$, and $4.1(t=1.9 \mathrm{~h}$; $n=0.874)$ to $3.8(t=23.3 \mathrm{~h} ; n=0.936)$, respectively. This confirms that the increasing bulk resistance was not caused by water entering the ISM. The somewhat higher dielectric constant of the CaSCISE membrane is probably due to the slight intermixing of the POT solid-contact layer with the outer ISM, but it is assumed that this will only have a minor influence on the bulk resistance and water uptake. 
The bulk resistance of the CaCWE membrane was practically constant for $24 \mathrm{~h}$ when the impedance spectra were measured in $10^{-3} \mathrm{M} \mathrm{KCl}$, in the absence of $\mathrm{Ca}^{2+}$, eliminating the possibility of ion exchange of $\mathrm{K}^{+}$for $\mathrm{Ca}^{2+}$ (Figure 5). It confirms that the increasing bulk resistance of the CaCWE and CaSCISE membranes observed in $10^{-3} \mathrm{M} \mathrm{CaCl}_{2}$ must be related to the formation of the $\mathrm{Ca}^{2+}$-ETH5234 complex with lower diffusivity than the free $\mathrm{K}^{+}$ions in the membrane phase. It is however, important to note that the changes in the low frequency region of the impedance spectra reflect the water uptake process at the substrate/ISM interface.

\subsection{Potentiometric Measurements}

The potentiometric measurements were done with the CaCWEs and CaSCISEs prepared on GC/PEEK substrates. The potential vs. time traces measured in $3 \times$ $10^{-12}-10^{-4} \mathrm{M} \mathrm{CaCl}_{2}$ solutions from high to low concentration showed that both electrode types had a fast potential response with electrode potentials stabilizing almost immediately after the concentration change, except for the CaSCISE at the highest $\mathrm{Ca}^{2+}$ concentrations (Figure 6a). The CaCWE and the CaSCISE had a limit of detection $(L O D)$ of $2 \times 10^{-8} \mathrm{M}$ and almost Nernstian slopes of $25.5 \pm 1.2$ and $27.3 \pm 0.1 \mathrm{mV} /$ decade, respectively (Figure $6 \mathrm{~b}$ and Table 2). The $L O D$ is slightly higher than for the corresponding SR-based CaSCISEs with POT or poly(aniline) (PANI) as the SC, which had $L O D \mathrm{~s}$ of $8 \times$ $10^{-9} \mathrm{M}$ and $2 \times 10^{-9} \mathrm{M}$, respectively [20,45]. Although POT is dissolved in the outer ISM, there is still enough of POT at the GC to facilitate the ion-to-electron transduction, which is reflected as better potential reproducibility of the CaSCISE $(148.9 \pm 1.0 \mathrm{mV} ; n=3)$ compared to the CaCWE (99.5 $\pm 12.2 \mathrm{mV} ; n=3)$ (Table 2).

The unbiased selectivity coefficients of $\mathrm{Ca}^{2+}$ against $\mathrm{Na}^{+}, \mathrm{K}^{+}, \mathrm{H}^{+}$and $\mathrm{Mg}^{2+}$ are almost the same for the

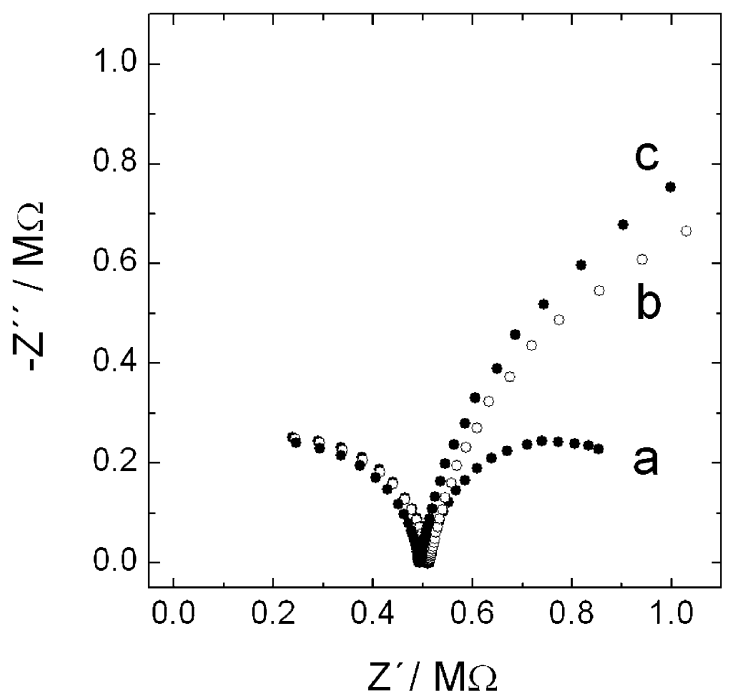

Fig. 5. Impedance spectra of the CaCWE (membrane thickness: $378 \mu \mathrm{m}$ ) measured in $10^{-3} \mathrm{M} \mathrm{KCl}$ at (a) $t=0.1$, (b) $t=11.6$ and (c) $t=23.3 \mathrm{~h} ; f=39.8 \mathrm{kHz}-10 \mathrm{mHz}, \Delta E=100 \mathrm{mV}$.

CaCWEs and CaSCISEs (Table 2). The slightly lower selectivities of the CaSCISE may possibly be caused by the dissolution of POT in the outer ISM which has previously been shown to decrease the membrane selectivity of plasticized PVC membranes containing PANI [46]. The influence of the conditioning time on the potentiometric response of the CaSCISE in $\mathrm{CaCl}_{2}$ solutions is shown in Figure 7. In contrary to the SR-based CaSCISEs, which could be calibrated without conditioning from $10^{-4} \mathrm{M}$ to $3 \times 10^{-12} \mathrm{M} \mathrm{CaCl}_{2}$, the PVC-based CaSCISEs had to be conditioned in $10^{-3} \mathrm{M} \mathrm{CaCl}_{2}$ at least for $24 \mathrm{~h}$ prior to the calibration to obtain a response curve without a superNernstian response at concentrations $<$ ca. $5 \times 10^{-6} \mathrm{M}$ $\mathrm{CaCl}_{2}$. This is a clear drawback in view of the application of the CaSCISEs as disposable single-use devices.

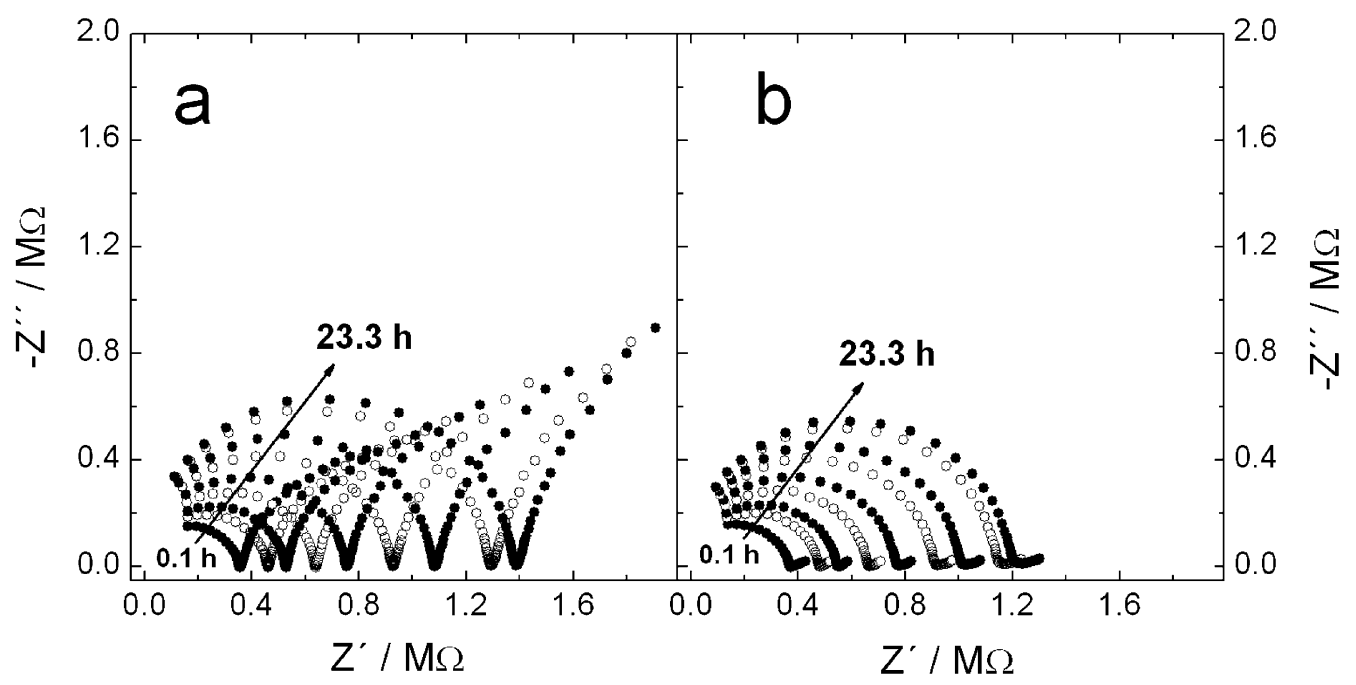

Fig. 4. Impedance spectra of (a) the CaCWE (membrane thickness: $250 \mu \mathrm{m}$ ) and (b) the CaSCISE (252 $\mu \mathrm{m}) \mathrm{measured}$ in $10^{-3} \mathrm{M}$ $\mathrm{CaCl}_{2}$ at $t=0.1,1.0,1.9,3.9,5.8,8.7,11.6,17.5$ and $23.3 \mathrm{~h} ; f=39.8 \mathrm{kHz}-10 \mathrm{mHz}, \Delta E=100 \mathrm{mV}$. 


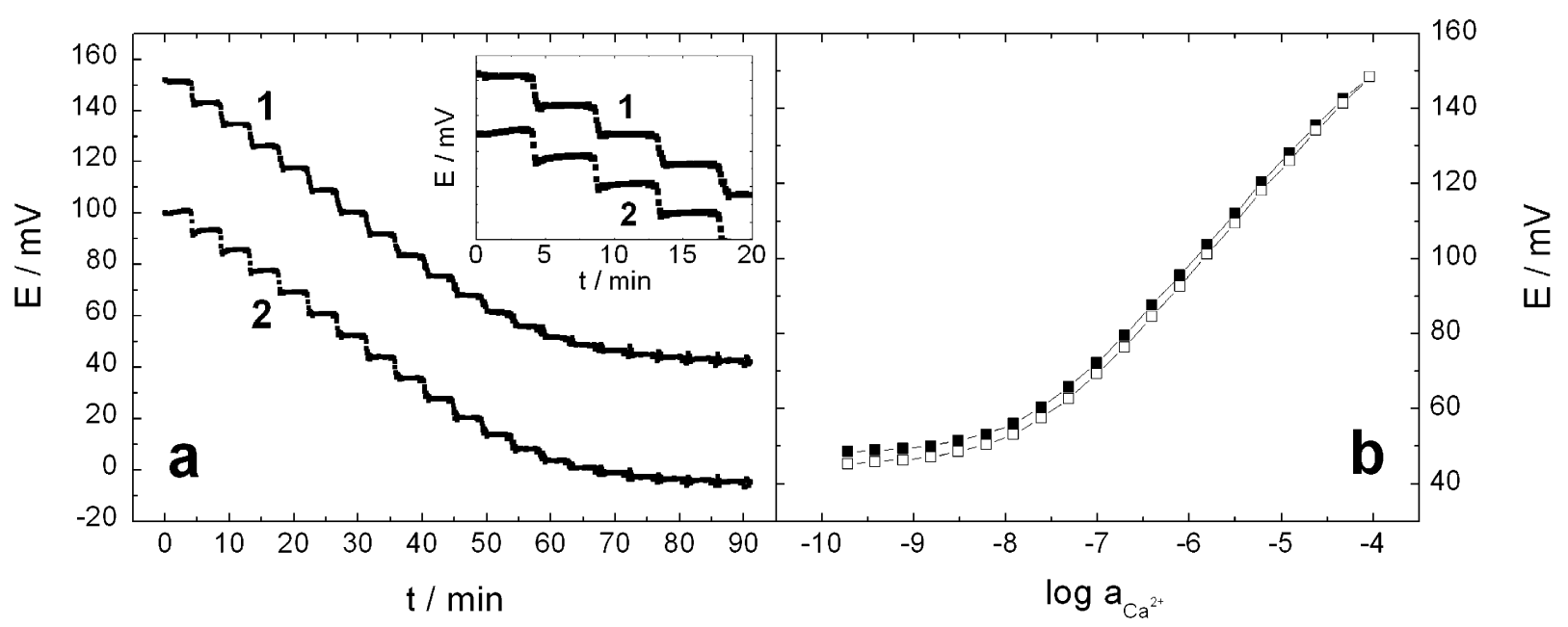

Fig. 6. (a) The potential-time traces of (1) the CaCWE and (2) the CaSCISE measured in $\mathrm{CaCl}_{2}$ solutions for 3 min at each concentration. Enlargements of the potential traces measured in the beginning of the calibrations are shown in the Inset. (b) The calibration plots of ( - ) the CaCWE (membrane thickness: $225 \mu \mathrm{m}$ ) and ( $\square$ ) the CaSCISE $(235 \mu \mathrm{m})$ in $\mathrm{CaCl}_{2}$ solutions. The calibration plot of the CaSCISE has been shifted to the same potential as for the CaCWE in $10^{-4} \mathrm{CaCl}_{2}$.

The potentiometric aqueous layer test revealed that the CaCWEs had potential responses typical for the aqueous layer formation [20]. The potential responses of the CaSCISEs were more difficult to interpret because their potential drifts differed from what the potentiometric aqueous layer theory predicts.

\section{Conclusions}

The water uptake, potential stability and bulk resistance of plasticized PVC-based CaCWEs and CaSCISEs have been measured simultaneously with a hyphenated

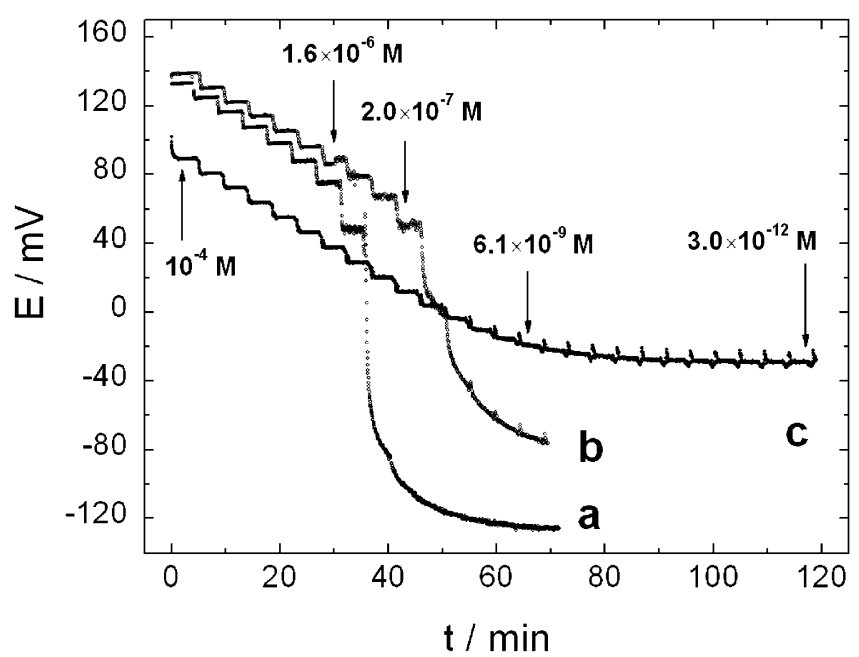

Fig. 7. The influence of the conditioning time on the potentiometric response of the PVC-based CaSCISE $(230 \mu \mathrm{m})$ in $\mathrm{CaCl}_{2}$ solutions: (a) Unconditioned electrode which was (b) first conditioned for $18 \mathrm{~h}$ in $10^{-4} \mathrm{M} \mathrm{CaCl}_{2}$ and (c) then in $10^{-3} \mathrm{M} \mathrm{CaCl}_{2}$ for $24 \mathrm{~h}$ (total conditioning time: $42 \mathrm{~h}$ ).
Table 2. Response characteristics of plasticized PVC-based CaCWEs and the CaSCISEs with POT as the SC.

\begin{tabular}{lll}
\hline$(n=3)$ & CaCWE & CaSCISE \\
\hline Slope $(\mathrm{mV} /$ dec $)[\mathrm{a}]$ & $25.5 \pm 1.2$ & $27.3 \pm 0.1$ \\
Potential reproducibility $(\mathrm{mV})[\mathrm{b}]$ & $99.5 \pm 12.2$ & $148.9 \pm 1.0$ \\
Detection limit $(\mathrm{M})$ & $2 \times 10^{-8}$ & $2 \times 10^{-8}$ \\
Selectivity coefficients $\left(\log K_{\mathrm{Ca}, \mathrm{j}}\right)$ & & \\
$j=\mathrm{Na}^{+}$ & $-3.3 \pm 0.2$ & $-3.1 \pm 0.1$ \\
$j=\mathrm{K}^{+}$ & $-3.1 \pm 0.1$ & $-2.9 \pm 0.1$ \\
$j=\mathrm{H}^{+}$ & $-2.4 \pm 0.1$ & $-2.3 \pm 0.1$ \\
$j=\mathrm{Mg}^{2+}$ & $-4.4 \pm 0.1$ & $-4.3 \pm 0.1$
\end{tabular}

[a] $2 \times 10^{-5}-10^{-7} \mathrm{M} \mathrm{CaCl}_{2}$. [b] Measured for three individual electrodes in $10^{-4} \mathrm{M} \mathrm{CaCl}_{2}$

method utilizing FTIR-ATR and EIS techniques. In contrary to SR-based ISMs and PMMA:PDMA membranes containing POT $[20,38]$, it is shown that the water uptake of PVC-based CaSCISE membranes with POT as the SC was higher in $10^{-3} \mathrm{M} \mathrm{CaCl}_{2}$ than for the $\mathrm{CaCWE}$ counterpart. The reason is probably related to the rather strong dissolution of the POT solid-contact in the outer ISM, although the fundamental reason is not known at the moment. This stresses the importance of developing preparation procedures for the PVC-based SCISEs which prevent the intermixing of the underlying SC with the ISM [47].

The CaCWE and CaSCISE membranes took up most of the water during the first $9 \mathrm{~h}$ in contact with $10^{-3} \mathrm{M}$ $\mathrm{CaCl}_{2}$, which was in good accordance with the time required for the potential of the CaCWEs and CaSCISEs to stabilize. The CaCWE had a lower potential drift indicating that the drift depended on the amount of water at the electrode substrate. The time-dependent increase of the bulk resistance of the ISMs was related to the exchange of $\mathrm{K}^{+}$for $\mathrm{Ca}^{2+}$ and the formation of the $\mathrm{Ca}^{2+}$-ionophore 
complex with a lower diffusivity than the free $\mathrm{K}^{+}$. This work shows that the water uptake is an important property that must be taken into consideration in the design of SCISEs with stable and driftless potentials.

\section{Acknowledgements}

This work is part of the activities of the Åbo Akademi Process Chemistry Centre within the Finnish Centre of Excellence Program (Academy of Finland) and connected to the scientific program of the development of quality-oriented and harmonized $\mathrm{R}+\mathrm{D}+\mathrm{I}$ strategy at BME. TL acknowledges the Academy of Finland for financial support. The financial support of the Hungarian Scientific Fund (OTKA NF 69262) and TÁMOP-4.2.1/B-09/1/ KMR-2010-0002 is also gratefully acknowledged.

\section{References}

[1] N. Oyama, T. Hirokawa, S. Yamaguchi, N. Ushizawa, T. Shimomura, Anal. Chem. 1987, 59, 258.

[2] A. Cadogan, Z. Gao, A. Lewenstam, A. Ivaska, D. Diamond, Anal. Chem. 1992, 64, 2496.

[3] J. Bobacka, M. McCarrick, A. Lewenstam, A. Ivaska, Analyst 1994, 119, 1985.

[4] A. Lewenstam, J. Bobacka, A. Ivaska, J. Electroanal. Chem. 1994, 368, 23.

[5] J. Bobacka, Z. Q. Gao, A. Ivaska, A. Lewenstam, J. Electroanal. Chem. 1994, 368, 33.

[6] A. Michalska, A. Hulanicki, A. Lewenstam, Analyst 1994, $119,2417$.

[7] J. Bobacka, A. Lewenstam, A. Ivaska, Talanta 1993, 40, 1437.

[8] M. Grzeszczuk, J. Bobacka, A. Ivaska, J. Electroanal. Chem. 1993, 362, 287.

[9] A. Ivaska, Electroanalysis 1991, 3, 247.

[10] A. Cadogan, A. Lewenstam, A. Ivaska, Talanta 1992, 39, 617.

[11] A. Michalska, A. Lewenstam, A. Ivaska, A. Hulanicki, Electroanalysis 1993, 5, 261.

[12] A. Lewenstam, A. Michalska, A. Ivaska, Chemia Analityczna 1995, 40, 587.

[13] T. Lindfors, A. Ivaska, J. Electroanal. Chem. 2002, 531, 43.

[14] T. Lindfors, H. Sandberg, A. Ivaska, Synth. Met. 2004, 142, 231.

[15] M. Fibbioli, W. E. Morf, M. Badertscher, N. F. de Rooij, E. Pretsch, Electroanalysis 2000, 12, 1286.

[16] M. Fibbioli, K. Bandyopadhyay, S. G. Liu, L. Echegoyen, O. Enger, F. Diederich, D. Gingery, P. Bühlmann, H. Persson, U. W. Suter, E. Pretsch, Chem. Mater. 2002, 14, 1721.

[17] Y. F. Li, R. Y. Qian, Synth. Met. 1993, 53, 149.

[18] T. Lindfors, F. Sundfors, L. Höfler, R. E. Gyurcsányi, Electroanalysis 2009, 21, 1914.
[19] F. Sundfors, T. Lindfors, L. Höfler, R. E. Gyurcsányi, Anal. Chem. 2009, 81, 5925.

[20] T. Lindfors, L. Höfler, G. Jágerszki, R. E. Gyurcsányi, Anal. Chem. 2011, 83, 4902.

[21] Z. Li, X. Z. Li, S. Petrovic, D. J. Harrison, Anal. Chem. 1996, 68, 1717.

[22] Z. Li, X. Z. Li, M. Rothmaier, D. J. Harrison, Anal. Chem. 1996, 68, 1726.

[23] R. De Marco, J.-P. Veder, G. Clarke, A. Nelson, K. Prince, E. Pretsch, E. Bakker, Phys. Chem. Chem. Phys. 2008, 10, 73.

[24] J. P. Veder, R. De Marco, G. Clarke, R. Chester, A. Nelson, K. Prince, E. Pretsch, E. Bakker, Anal. Chem. 2008, 80, 6731.

[25] J. P. Veder, K. Patel, G. Clarke, E. Grygolowicz-Pawlak, D. S. Silvester, R. De Marco, E. Pretsch, E. Bakker, Anal. Chem. 2010, 82, 6203.

[26] C. Appiah-Kusi, S. J. Kew, E. Hall, Electroanalysis 2009, 21, 1992.

[27] E. Malinowska, V. Oklejas, R. W. Hower, R. B. Brown, M. E. Meyerhoff, Sens. Actuators B 1996, 33, 161.

[28] K. Kimura, T. Sunagawa, M. Yokoyama, Anal. Chem. 1997, 69, 2379.

[29] I. A. Mostert, P. Anker, H. B. Jenny, U. Oesch, W. E. Morf, D. Ammann, W. Simon, Mikrochim. Acta 1985, 1, 33.

[30] G. S. Cha, D. Liu, M. E. Meyerhoff, H. C. Cantor, A. R. Midgley, H. D. Goldberg, R. B. Brown, Anal. Chem. 1991, $63,1666$.

[31] G. Marrazza, M. Mascini, Electroanalysis 1992, 4, 41.

[32] M. E. Poplawski, R. B. Brown, K. L. Rho, S. Y. Yun, H. J. Lee, G. S. Cha, K. J. Paeng, Anal. Chim. Acta 1997, 355, 249.

[33] I. J. Yoon, D. K. Lee, H. Nam, G. S. Cha, T. D. Strong, R. B. Brown, J. Electroanal. Chem. 1999, 464, 135.

[34] L. Y. Heng, E. A. H. Hall, Anal. Chem. 2000, 72, 42.

[35] L. Y. Heng, E. A. H. Hall, Anal. Chim. Acta 1996, 324, 47.

[36] A. Shatkay, Anal. Chem. 1967, 39, 1056.

[37] Diffusion in Polymers (Ed: P. Neogi), Marcel Dekker, New York 1996

[38] F. Sundfors, L. Höfler, R. Gyurcsányi, T. Lindfors, Electroanalysis 2011, 23, 1769

[39] T. Lindfors, J. Bobacka, A. Lewenstam, A. Ivaska, Analyst 1996, $121,1823$.

[40] J. Bobacka, Anal. Chem. 1999, 71, 4932.

[41] S. Bodor, J. M. Zook, E. Lindner, K. Tóth, R. E. Gyurcsányi, Analyst 2008, 133, 635.

[42] R. D. Armstrong, M. Todd, Electrochim. Acta 1987, 32, 155.

[43] R. D. Armstrong, P. Nikitas, Electrochim. Acta 1985, 30, 1627.

[44] Y. Qin, Y. M. Mi, E. Bakker, Anal. Chim. Acta 2000, 421, 207.

[45] T. Lindfors, J. Szúcs, F. Sundfors, R. E. Gyurcsányi, Anal. Chem. 2010, 82, 9425.

[46] J. Bobacka, T. Lindfors, M. McCarrick, A. Ivaska, A. Lewenstam, Anal. Chem. 1995, 67, 3819.

[47] T. Lindfors, H. Aarnio, A. Ivaska, Anal. Chem. 2007, 79, 8571. 